\title{
PENGARUH PRAKTEK PENGALAMAN LUAR, DAN MOTIVASI MASUK DUNIA KERJA TERHADAP KESIAPAN KERJA MAHASISWA PERBANKAN SYARIAH DI LEMBAGA KEUANGAN SYARIAH
}

Oleh:

\author{
Herlina Yustati ${ }^{1}$ \\ Lucy Auditya ${ }^{2}$ \\ Fakultas Ekonomi dan Bisnis Islam \\ Institut Agama Islam Negeri Bengkulu \\ Email: \\ herlinayustati@iainbengkulu.ac.id
}

\begin{abstract}
ABSTRAK
Penelitian ini bertujuan untuk melihat pengaruh Praktik Pengalaman Luar dan Motivasi Memasuki Dunia Kerja terhadap Keiapan Kerja mahasiswa Program Studi Perbankan Syariah di Lembaga Keuangan Syariah.Metode yang digunakan adalah kuantitafi dengan menyebarkan kuesioner di kalangan mahasiswa.Hasil peneltian menunujukkan bahwa secara simultan Praktik Pengalaman luar (PPL)dan motivasi memasuki dunia kerja memiliki pengaruh signifikan terhadap kesiapan memasuki dunia kerja.Demikian juga secara parsial hasil penelitian menunjukkan bahwa Praktik Pengalaman Luar memiliki pengaruh terhadap kesiapan kerja, motivasi memasuki dunia kerja berpengaruh signifikan terhadap kesiapan memasuki dunia kerja. Kontribusi yang diberikan oleh Variabel Praktik Pengalaman Luar dan Motivasi memasuki dunia kerja sebesar 69,8\% dalam mempengaruhi kesiapan kerja mahasiswa. Sisanya 30,2\% dipengaruhi oleh variabel lain yang tidak diteliti dalam penelitian ini.
\end{abstract}

Kata Kunci :Keaktifan Mahasiswa, Kesiapan Kerja, Praktik Pengalaman Luar $(P P L)$

\section{A. PENDAHULUAN}

Pada era global saat ini menuntut semua pihak dalam berbagai bidang tidak terkecuali bidang pendidikan untuk senantiasa untuk meningkatkan kompetensinya.Dengan demikian diharapkan dunia pendidikan mampu menyiapkan manusia yang sudah siap kerja. Hal ini disebabkan karena kualitas sumber daya manusia memiliki peranan penting dalam kemajuan dan kemakmuran suatu bangsa(Handayani \& Rediana Setiyani, 2015).

Masalah SDM tidak bisa lepas dari masalah tenaga kerja.Kualitas tenaga kerja sangat bergantung pada kualitas SDM.Oleh karena itu, kualitas SDM harus mendapatkan prioritas utama untuk ditingkatkan dan dikembangkan guna 
mendapatkan kualitas tenaga kerja yang baik.Ketidakmampuan dalam meningkatkan daya saing sumber daya manusia(SDM) nasional, menyebabkan semakin terpuruknya posisi Indonesia dalam kancah persaingan global apabila tidak secara sungguh-sungguh mempersiapkan diri dengan berbagai keunggulan untuk menghadapi persaingan yang akan terus berkembang secara ketat dan semakin tajam. Pertambahan penduduk yang tidak memiliki keterampilan kerja akan mengakibatkan Indonesia menjadi salah satu pasar utama bagi produkproduk asing dan pasar lapangan kerja bagi tenaga asing, serta akan menjadi bencana bagi Indonesia jika tidak diikuti dengan peningkatan kualitas SDM. Oleh karena itu, era ini menuntut tenaga kerja sebagai sumber daya berkualitas yang mampu berkompetisi dalam bidang teknologi dengan bekal keahlian yang profesional di bidangnya supaya dapat memenuhi kebutuhan hidup yang semakin kompleks.(Kementerian Tenaga Kerja dan Transmigrasi, 2011).

Peningkatan kemampuan dan keterampilan bagi generasi muda sebagai calon tenaga kerja merupakan tanggung jawab dunia pendidikan, baik pendidikan formal maupun nonformal. Pendidikan merupakan bagian integral yang tidakdapat dipisahkan dari proses penyiapan SDM yang berkualitas, tangguh, dan terampil. Dengan kata lain, melalui pendidikan akan diperoleh calon tenaga kerja yang berkualitas sehingga lebih produktif dan mampu bersaing dengan negara lain.

Kesiapan kerja adalah keseluruhan kondisi individu yang meliputi kematangan fisik, mental dan pengalaman serta adanya kemauan dan kemampuan untuk melaksanakan suatu pekerjaan atau kegiatan. Kesiapan kerja sangat penting dimiliki oleh seorang mahasiswa, karena mahasiswa merupakan harapan masyarakat untuk menjadi lulusan sarjana yang mempunyai kompetensi sesuai dengan bidang keahliannya diterima di dunia kerja atau mampu mengembangkan melalui wirausaha.

Kesiapan kerja terbentuk dari tiga aspek yang mendukung, yaitu: aspek penguasaan pengetahuan, penguasaan sikap kerja, dan aspek penguasaan keterampilan kerja yang dimiliki mahasiswa. Salah satu usaha perguruan tinggi dalam mempersiapkan mahasiswa memasuki dunia kerja adalah dengan menerapkan Praktik Pengalaman Luar sebagai salah satu mata kuliah yang harus diambil oleh mahasiswa.

Dalam pelaksanaannnya, mahasiswa diharapkan tidak hanya mampu mengaplikasikan segala ilmu dan teori-teori yang telah didapatkan di bangku perkuliahan, tetapi juga harus mampu menimba pengetahuan baru dan bekerja sama di tempat mahasiswa melaksanakan Praktik Pengalaman Luar. Praktek Pengalaman Luar di Fakultas Ekonomi dan Bisnis Islam di laksanakan dengan 2 metode, yaitu PPL Berbasis Administrasi dan PPL berbasis Industri. (PPL) berbasis Administrasi Perkantoran dilaksanakan selama 1 (satu) bulan setara dengan 30 (tiga puluh) hari, sedangkan Praktek Pengalaman Lapangan (PPL) berbasis Industri waktu disesuaikan dengan kesediaan lembaga menerima peserta Praktek Pengalaman Lapangan (PPL). Dengan dilaksanakan PRaktik pengalaman luar diharapkan memilik pengaruh terhadap kesiapan kerja mahasiswa Program studi perbankan syariah di lembaga keuangan syariah nantinya.

Selain melaksanakan praktik pengalam Luar bagi mahasiswa diharpakan mahasiswa juga memiliki motivasi yang kuat untuk memasuki dunia kerja, karena 
dengan memiliki motivasi yang kuat maka akan memiliki kesiapan yang matang dalam memasuki dunia kerja. Berdasarkan latar belakang di atas maka tujuan penelitian ini adalah untuk melihat pengaruh Praktik Pengalaman Luar dan Motivasi memasuki dunia kerja terhadap kesiapan Kerja di Lembaga Keuangan Syariah pada mahasiswa Perbankan Syariah IAIN Bengkulu.

\section{B. KAJIAN PUSTAKA}

\section{Kesiapan Kerja}

Kesiapan menurut kamus psikologi adalah "Tingkat perkembangan dari kematangan atau kedewasaan yang menguntungkan untuk mempraktikkan sesuatu" menurut Chalpin, dikemukakan juga bahwa "Kesiapan meliputi kemampuan untuk menempatkan dirinya jika akan memulai serangkaian gerakan yang berkaitan dengan kesiapan mental dan jasmani (Sutrisno, 2009). Kesiapan adalah tingkatan atau keadaaan yang harus dicapai dalam proses perkembangan perorangan pada tingkatan pertumbuhan mental, fisik, sosial dan emosional ((Oemar Hamalik, 2008).

Menurut Kamus Besar Bahasa Indonesia "Kerja diartikan sebagai kegiatan untuk melakukan sesuatu yang dilakukan atau diperbuat dan sesuatu yang dilakukan untuk mencari nafkah, mata pencaharian (Depdiknas, 2005). Kerja diartikan sebagai suatu kelompok aktivitas, tugas, atau kewajiban yang sama dan dibayar, yang memerlukan atribut-atribut yang sama dalam suatu organisasi tertentu (Manribu, 1998).

Kesiapan kerja adalah kemampuan seseorang untuk melaksanakan pekerjaan dengan baik di dalam maupun di luar hubungan kerja guna menghasilkan barang atau jasa (Kartini Kartono, 1991). kesiapan kerja adalah daftar perilakuyang bersangkutan dengan mengidentifikasi, memilih, merencanakan dan melaksanakan tujuantujuan bekerja yang tersedia bagi individu tertentu sesuai dengan usia perkembangannya (Manribu, 1998).Faktor- faktor yang mempengaruhi Kesiapan Kerja antara lain a) Motivasi Belajar; b) Pengalaman Praktik Luar; c) Bimbingan Vokasional; d) Latar Belakang Ekonomi Orang Tua; e) Prestasi Belajar Sebelumnya; f) Informasi Pekerjaan; g) Ekspektasi Masuk Dunia kerja

\section{Praktik Pengalaman Luar}

Pengalaman adalah pengetahuan atau keterampilan yang diperoleh dari praktik atau dari luar usaha belajar".Pengalaman merupakan pengetahuan atau keterampilan yang diketahui dan dikuasai seseorang sebagai akibat dari perbuatan atau pekerjaan yang telah dilakukan sebelumnya selama jangka waktu tertentu. Seseorang dikatakan berpengalaman apabila telah memiliki tingkat penguasaan pengetahuan dan keterampilan yang relevan dan memadai sesuai dengan bidang keahliannya(Chalpin J.P, 2006). Pengalaman adalah sumber pengetahuan dan pengalaman diperoleh karena adanya interaksi antara individu dengan lingkungannya (Oemar Hamalik, 2008). 
Definisi-definisi di atas dapat disimpulkan bahwa pengalaman adalah suatu tingkat penguasaan dan pemahaman seseorang berdasarkan bidang yang diminatinya dan dapat diukur dari lamanya belajar serta tingkat pengetahuan dan keterampilan yang dimiliki.

Pengalaman dapat diperoleh melalui pendidikan dan pelatihan.Pada dasarnya pendidikan dimaksud guna mempersiapkan tenaga kerja sebelum memasuki lapangan pekerjaan agar pengetahuan dan keterampilan yang diperoleh sesuai dengan syarat yang dikehendaki oleh suatu jenis pekerjaan. Dengan cara belajar, belajar adalah syarat mutlak untuk menjadi pandai dalam segala hal, baik dalam bidang ilmu pengetahuan maupun keterampilan atau kecakapan (Dalyono, 2015).

\section{Motivasi Memasuki Dunia Kerja}

Kesiapan kerja mahasiswa salah satunya dapat dipengaruhi oleh kematangan mental.Kematangan mental ini dapat dilihat dari tinggi rendahnya motivasi memasuki dunia kerja yang ada pada diri mahasiswa. Bagi mahasiswa, peran motivasi pada diri mereka menjadi sangat penting karena motivasi ini yang akan memberikan dorongan dan semangat untuk bekerja. Adanya motivasi kerja yang tinggi akan mendorong mahasiswa untuk sebanyak mungkin membekali diri dengan berbagai kompetensi yang diperlukan dalam bekerja sehingga kesiapan kerja yang dimiliki menjadi memadai.

\section{METODE PENELITIAN}

Penelitian ini menggunakan pendekatan kuantitatif.Populasi penelitian adalah 421 Orang.Metode pengambilan sampel yang digunakan adalah metode incidental sampling.Untuk menentukan sample (sample size) digunakan rumus slovin sehingga sampel yang digunakan sebanyak 81 Orang.Jenis data yang digunakan dalam penelitian ini adalah data primer dan sekunder.Data primer didapatkan dari penyebaran angket kuisioner dan data sekunder didapatkan dari program studi Perbankan Syariah IAIN Bengkulu.Teknik analisis data yang digunakan adalah analisis deskriptif, uji asumsi klasik, analisis regresi berganda, uji hipotesis serta uji kelayakan model.

\section{HASIL DAN PEMBAHASAN}

Penelitian ini menganalisis pengaruh dua variable bebas yaitu Praktik Pengalaman Luar $\left(\mathrm{X}_{1}\right)$, Motivasi Memasuki Dunia Kerja $\left(\mathrm{X}_{2}\right)$ yang mempengaruhi kesiapan kerja mahasiswa Program Studi Perbankan Syariah IAIN Bengkulu di Lembaga Keuangan Syariah.Analisis dilakukan dengan persamaan regresi berganda sebagai berikut: 


$$
\begin{gathered}
Y=a_{0}+b_{1} X_{1}+b_{2} X_{2}+\epsilon \\
Y=2,885+0,629 X_{1}+0,551 X_{2}+\epsilon
\end{gathered}
$$

Dimana:

$$
\begin{aligned}
\mathrm{Y}= & \text { Kesiapan Kerja di Lembaga Keuangan Syariah } \\
\mathrm{a}_{0}= & \text { Konstanta } \\
\mathrm{b}_{1,2}= & \text { koefisen regresi dari variabel independent } \\
\mathrm{X}_{1}= & \text { Praktik Pengalaman Luar } \\
\mathrm{X}_{2}= & \text { Motivasi memasuki dunia kerja } \\
e & =\begin{array}{l}
\text { Epsilon (variabel- variabel independen lain yang tidak diukur dalam } \\
\end{array}
\end{aligned}
$$

Interpretasi persamaan di atas dapat dijelaskan bahwa:

1. Nilai konstanta sebesar 2.885 artinya apabila PPL $\left(\mathrm{X}_{1}\right)$ dan motivasi memasuki dunia kerja $\left(\mathrm{X}_{2}\right)$ dalam konstansta atau 0, maka kesiapan kerja nilainya sebesar 2.885 .

2. Variabel PPL sebesar 0,629 artinya setiap kenaikan satu variabel PPL $\left(\mathrm{X}_{1}\right)$ mahasiswa alami, maka kesiapan kerja (Y) akan naik sebesar 0,629 dengan asumsi bahwa variabel bebas yang lain dari model regresi adalah tetap.

3. Variabel motivasi memasuki dunia kerja sebesar 0,551 artinya setiap kenaikan satu variabel motivasi memasuki dunia kerja $\left(\mathrm{X}_{2}\right)$ mahasiswa alami, maka kesiapan kerja (Y) akan naik sebesar 0,551 dengan asumsi bahwa variabel bebas yang lain dari model regresi adalah tetap.

Tabel 1. (Uji F/Simultan)

Hasil Uji F

\begin{tabular}{l|c|c|c|c|c}
\hline Model & Sum of Squares & Df & $\begin{array}{c}\text { Mean } \\
\text { Square }\end{array}$ & F & Sig. \\
\hline 1 Regression & 261.984 & 2 & 130.992 & $94.591 .000^{\mathrm{a}}$ \\
Residual & 108.016 & 78 & 1.385 & & \\
Total & 370.000 & 80 & & \\
\hline \multicolumn{6}{c}{ Sumber : Data Primer diolah, 2019}
\end{tabular}

Uji Fdigunakan untuk mengetahui apakah variabel PPL $\left(\mathrm{X}_{1}\right)$ dan Motivasi memasuki dunia kerja $\left(\mathrm{X}_{2}\right)$ secara simultan berpengaruh signifikan terhadap kesiapan kerja (Y). Hasil pengujian dapat dilihat sebagai berikut:

Berdasarkan hasil uji $\mathrm{F}$ pada tabel 4.13 diatas dapat diketahuibahwa nilai signifikansi $(0,000)<(\alpha) 0,05$, maka disimpulkan bahwa PPL dan Motivasi memasuki dunia kerja secara simultan berpengaruh signifikan terhadap kesiapan kerja.

Hasil penelitian ini diperkuat oleh kajian teori, dimana kajian teori tersebut mengatakan bahwa terdapat banyak faktor yang mempengaruhi kesiapan kerja baik internal maupun eksternal.Faktor internal meliputi kematangan baik fisik maupun mental, tekanan, kreativitas, minat, bakat, intelegensi, kemandirian, 
penguasaan ilmu pengetahuan, prestasi belajar, motivasi, kepribadian, cita-cita. Sedangkan faktor eksternal yaitu keadaan ekonomi keluarga, peran masyarakat, keluarga, sarana, dan prasarana sekolah, informasi dunia(Jumaidi, Armida, \& Susanti, 2018).

Tabel 2.Hasil Uji-t/Parsial

\begin{tabular}{|c|c|c|c|c|}
\hline \multirow[t]{2}{*}{ Model } & \multicolumn{3}{|c|}{ Unstandardized Standardized } & \multirow[t]{2}{*}{ Sig. } \\
\hline & $\mathrm{B}$ & Std. Error & Beta & \\
\hline (Constant) & 2.885 & .986 & & 2.927 .004 \\
\hline PPL & .462 & .075 & .446 & 6.169 .000 \\
\hline MOTIVASI & .483 & .068 & .514 & 7.102 .000 \\
\hline
\end{tabular}

Uji t bertujuan untuk mengetahui apakah PPL $\left(\mathrm{X}_{1}\right)$ dan Motivasi memasuki dunia kerja $\left(\mathrm{X}_{2}\right)$ secara persial berpengaruh signifikan terhadap kesiapan kerja (Y).Berdasarkan hasil penelitian diketahui bahwa Praktik Pengalaman Luar berpengaruh signifikan terhadap kesiapan kerja mahasiswa perbankan syariah di Lembaga Keuangan Syariah dengan nilai signifikansi $0.000<0.05$. Hal ini menunjukkan bahwa semakin baik dalam melaksanakan praktik pengalaman Luar maka akan semakin baik juga kesiapan mahasiwa dalam memasuki dunia kerja.

Hal ini sependapat dengan penelitain Ahmad Awaludin Baitu dan Sudji Munadi bahwa terdapat pengaruh antara pengalaman praktik terhadap kesiapan kerja siswa SMK Program Studi Keahlian Teknik Elektronika seluruh Kabupaten Sleman(Baiti \& Munadi, 2014). Dan sependapat juga dengan penelitian Ufi Naili Fajriah dan Ketut Sudrama bahwa ada pengaruh positif praktik kerja industri terhadap kesiapan kerja siswa (Fajriah \& Sudarma, 2017).

Uji $t$ bertujuan untuk mengetahui apakah PPL $\left(\mathrm{X}_{1}\right)$ dan Motivasi memasuki dunia kerja $\left(\mathrm{X}_{2}\right)$ secara persial berpengaruh signifikan terhadap kesiapan kerja (Y).Berdasarkan hasil penelitian diketahui bahwa Praktik Motivasi memasuki dunia kerja berpengaruh signifikan terhadap kesiapan kerja mahasiswa perbankan syariah di Lembaga Keuangan Syariah dengan nilai signifikansi $0.000<0.05$. Hal ini menunjukkan bahwa semakin baik dalam memotivasi diri memasuki dunia kerja maka akan semakin baik juga kesiapan mahasiwa dalam memasuki dunia kerja.

Hasil penelitian ini sependapat dengan penelitian Ufi Naili Fajriah dan Ketut Sudrama bahwa ada pengaruh positif motivasi memasuki dunia kerja terhadap kesiapan kerja siswa(Fajriah \& Sudarma, 2017). Dan senada juga dengan penelitian Nia Junaidi, Armida, Dessi Susanti bahwa motivasi memasuki dunia kerja mempengaruhi kesiapan kerja mahasiswa jurusan pendidikan ekonomi FE UNP di era MEA. Apabila motivasi memasuki dunia kerja semakin tinggi, maka akan membuat tingkat kesiapan kerja yang tinggi pula. Hal ini juga sesuai dengan pendapat Kardimin dalam Aulia (2017) bahwa salah satu faktor yang mempengaruhi kesiapan kerja adalah motivasi(Jumaidi et al., 2018). 
Tabel 3.

Kontribusi Pengalaman Praktik Luar Dan Motivasi Memasuki Dunia Kerja Terhadap Kesiapan Kerja

\begin{tabular}{ccccc}
\hline \multicolumn{5}{c}{ Model Summary } \\
\hline Model & $\mathrm{R}$ & R Square & $\begin{array}{c}\text { Adjusted R } \\
\text { Square }\end{array}$ & $\begin{array}{c}\text { Std. Error of the } \\
\text { Estimate }\end{array}$ \\
\hline 1 & $.840^{\mathrm{a}}$ & $\mathbf{. 7 0 5}$ & .698 & 1.181 \\
\hline a. Predictors: (Constant), ORGANISASI, PPL & &
\end{tabular}

Dari Tabel 3 dapat menunjukkan besarnya Adjusted R square sebesar 0,698 atau 69,8 \%. Dapat diartikan bahwa 69,8 \% kesiapan kerja mahasiswa Program Studi Perbankan Syariah untuk bekerja di Lembaga Keuangan Syariah dipengaruhi oleh variable Praktik Pengalaman Lapangan dan motivasi memasuki dunia. Sedangkan sisanya 30,2 \% dipengaruhi oleh variabel lain selain Praktik Pengalaman Luar dan motivasi memasuki dunia kerja.

\section{E. KESIMPULAN}

Berdasarkan analisa dan pembahasan dapat disimpulkan bahwa:

1. Secara simultan PPL $\left(X_{1}\right)$ dan Motivasi memasuki dunia kerja $\left(X_{2}\right)$ berpengaruh signifikan terhadap kesiapan kerja (Y) hal ini dibuktikan dengan hasil uji $\mathrm{F}$ dengan nilai signifikansi $(0,000)<(\alpha) 0,05$.

2. Praktik Pengalaman Luar berpengaruh signifikan terhadap kesiapan kerja mahasiswa perbankan syariah di Lembaga Keuangan Syariah dengan nilai signifikansi $0.000<0.05$. Hal ini menunjukkan bahwa semakin baik dalam melaksanakan praktik pengalaman Luar maka akan semakin baik juga kesiapan mahasiwa dalam memasuki dunia kerja.

3. Motivasi memasuki dunia kerja berpengaruh signifikan terhadap kesiapan kerja mahasiswa perbankan syariah di Lembaga Keuangan Syariah dengan nilai signifikansi $0.000<0.05$. Hal ini menunjukkan bahwa semakin baik dalam memotivasi diri memasuki dunia kerja maka akan semakin baik juga kesiapan mahasiwa dalam memasuki dunia kerja.

4. 69,8 \% kesiapan kerja mahasiswa Program Studi Perbankan Syariah untuk bekerja di Lembaga Keuangan Syariah dipengaruhi oleh variable Praktik Pengalaman Lapangan dan motivasi memasuki dunia. Sedangkan sisanya 30,2 \% dipengaruhi oleh variabel lain selain Praktik Pengalaman Luar dan motivasi memasuki dunia kerja. 


\section{DAFTAR PUSTAKA}

Baiti, A. A., \& Munadi, S. (2014). Pengaruh pengalaman praktik, prestasi belajar dasar kejuruan dan dukungan orang tua terhadap kesiapan kerja siswa SMK. Jurnal Pendidikan Vokasi, 4(2), 164-180. https://doi.org/10.21831/jpv.v4i2.2543

Chalpin J.P. (2006). Kamus Lengkap Psikologi. Jakarta: PT. RajaGrafindo Persada.

Dalyono. (2015). Psikologi Pendidikan. Jakarta: Rineka Cipta.

Depdiknas, P. B. (2005). Kamus Besar Bahasa Indonesia. Jakarta: Balai Pustaka.

Fajriah, U. N., \& Sudarma, K. (2017). Pengaruh Praktik Kerja Industri, Motivasi Memasuki Dunia Kerja, Dan Bimbingan Karir Pada Kesiapan Kerja Siswa. Economic Education Analysis Journal, 6(2), 421-432.

Handayani, U. S., \& Rediana Setiyani. (2015). Pengaruh Prestasi Akademik Mata Diklat Produktif Akuntansi, Praktik Kerja Industri, Dan Lingkungan Keluarga Terhadap Kesiapan Kerja Siswa Kelas Xii Smk Negeri 1 Kebumen Program Keahlian Akuntansi Tahun Ajaran 2014/2015. Economic Education Analysis Journal, 4(3), 864-875.

Jumaidi, N., Armida, \& Susanti, D. (2018). PENGARUH MOTIVASI MEMASUKI DUNIA KERJA DAN PRESTASI BELAJAR TERHADAP KESIAPAN KERJA MAHASISWA JURUSAN PENDIDIKAN EKONOMI FAKULTAS EKONOMI UNIVERSITAS NEGERI PADANG. EcoGen, 1(2016), 955-966.

Kartini Kartono. (1991). Menyiapkan dan Memandu Karier. Jakarta: Rajawali Pers.

Manribu, M. T. (1998). Pengantar Bimbingan dan Konseling karir. Jakarta: Depdikbud.

Oemar Hamalik. (2008). Proses Belajar Mengajar. Jakarta: Bumi Aksara.

Sutrisno, E. (2009). Manajemen Sumber Daya Manusia. Surabaya: Kencana.

Baiti, A. A., \& Munadi, S. (2014). Pengaruh pengalaman praktik, prestasi belajar dasar kejuruan dan dukungan orang tua terhadap kesiapan kerja siswa SMK. Jurnal Pendidikan Vokasi, 4(2), 164-180. https://doi.org/10.21831/jpv.v4i2.2543

Chalpin J.P. (2006). Kamus Lengkap Psikologi. Jakarta: PT RajaGrafindo Persada.

Dalyono. (2015). Psikologi Pendidikan. Jakarta: Rineka Cipta.

Depdiknas, P. B. (2005). Kamus Besar Bahasa Indonesia. Jakarta: Balai Pustaka.

Fajriah, U. N., \& Sudarma, K. (2017). Pengaruh Praktik Kerja Industri, Motivasi Memasuki Dunia Kerja, Dan Bimbingan Karir Pada Kesiapan Kerja Siswa. Economic Education Analysis Journal, 6(2), 421-432. 
Handayani, U. S., \& Rediana Setiyani. (2015). Pengaruh Prestasi Akademik Mata Diklat Produktif Akuntansi, Praktik Kerja Industri, Dan Lingkungan Keluarga Terhadap Kesiapan Kerja Siswa Kelas Xii Smk Negeri 1 Kebumen Program Keahlian Akuntansi Tahun Ajaran 2014/2015. Economic Education Analysis Journal, 4(3), 864-875.

Jumaidi, N., Armida, \& Susanti, D. (2018). PENGARUH MOTIVASI MEMASUKI DUNIA KERJA DAN PRESTASI BELAJAR TERHADAP KESIAPAN KERJA MAHASISWA JURUSAN PENDIDIKAN EKONOMI FAKULTAS EKONOMI UNIVERSITAS NEGERI PADANG. EcoGen, 1(2016), 955-966.

Kartini Kartono. (1991). Menyiapkan dan Memandu Karier. Jakarta: Rajawali Pers.

Manribu, M. T. (1998). Pengantar Bimbingan dan Konseling karir. Jakarta: Depdikbud.

Oemar Hamalik. (2008). Proses Belajar Mengajar. Jakarta: Bumi Aksara.

Sutrisno, E. (2009). Manajemen Sumber Daya Manusia. Surabaya: Kencana. 